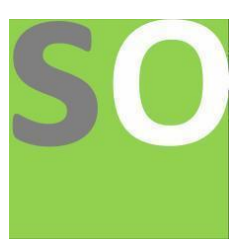

Article title: Chewing Khat Habit among Students of Dire Dawa University Ethiopia

Authors: Mustefa Jibril[1]

Affiliations: Dire Dawa University, Dire Dawa, Ethiopia[1]

Orcid ids: 0000-0002-3165-2410[1]

Contact e-mail: mustefazinet1981@gmail.com

License information: This work has been published open access under Creative Commons Attribution License $\mathrm{http}: / / c r e a t i v e c o m m o n s . o r g / l i c e n s e s / b y / 4.0 /$, which permits unrestricted use, distribution, and reproduction in any medium, provided the original work is properly cited. Conditions, terms of use and publishing policy can be found at https://www.scienceopen.com/.

Preprint statement: This article is a preprint and has not been peer-reviewed, under consideration and submitted to ScienceOpen Preprints for open peer review.

DOI: 10.14293/S2199-1006.1.SOR-.PPCMOCU.v1

Preprint first posted online: 04 October 2021

Keywords: Chewing Khat, Health effects, Dire Dawa University students 


\title{
Chewing Khat Habit among Students of Dire Dawa University Ethiopia
}

\author{
Mustefa JIBRIL \\ School of Electrical \& Computer Engineering, Dire Dawa Institute of Technology, Dire Dawa, \\ Ethiopia \\ mustefa.jibril@ddu.edu.et
}

\begin{abstract}
Chewing Khat is one of the leading causes of mental disorders in Ethiopia. An alarming increase in Khat chewing among adults since the early 1990s was reported. Studies have shown that starting chewing Khat early in life is associated with an increased risk of adverse health effects. The objective of the study: This study was conducted to measure the increase in Khat chewing among students at Dire Dawa University students in Dire Dawa City, identify the natural causes of the problem, and demonstrate students' knowledge of the effects of Khat chewing. Material and Methods: The study was separate. Dated February 2021. Students during study time $(\mathrm{n}=302)$ were included. The information was collected through personal interviews and completed a list of questions prepared after reviewing. RESULTS: Male (88.2\%) of responding students chewed Khat with a significant difference $(\mathrm{P}<0.001)$ between males and females in terms of chewing. The year of student study, academic achievement, and family history of chewing Khat had a significant impact $(\mathrm{P}<0.05)$ on chewer students. Of the Khat chewer students who read 35.6\% reported chewing both morning and afternoon. $66.7 \%$ of students who chewed reported that they had intentions to stop chewing and $82.4 \%$ considered chewing to be dangerous. CONCLUSION: Khat chewing gum among students is considered a problem and efforts are needed to help students stop chewing and this is considered a way to prevent Khat chewing among students.
\end{abstract}

Keywords: Chewing Khat, Health effects, Dire Dawa University students

\section{Introduction:}

Khat or qat is a flowering plant native to the East Hararghe Zone and the West Hararghe Zone of Ethiopia. The khat law varies by region. In many countries, khat may not be a controlled substance but may be illegal under normal laws. It is directly regulated in certain countries including Canada, Germany, the United Kingdom, and the United States. In contrast, their production, sale, and use are legal in countries where their use is customary in those cultures, including Djibouti, Kenya, Uganda, Ethiopia, Somalia, and Yemen. In Israel, which retains the population of Yemenite Jews, the use of plant leaves in natural conditions is only permitted. [1] The use of Khat causes little excitement and happiness, similar to that given to strong coffee. [2] People talk a lot under the influence of the plant. Animal studies have shown that khat causes an increase in motor activity. [3] The effects of oral administration of cathinone occur much faster than the effects of amphetamine pills; about 15 minutes compared to 30 minutes on amphetamine. Khat can cause male behavior and excessive behavior, with similar effects to those produced by amphetamine. [4]

Consumption of khat leads to constipation. Exhausted students (mydriasis) are prominent during the use of khat, which shows the effects of drug therapy, which also shows increased heart rate and blood pressure. Long-term use can reduce permanent tooth decay (greenish tinge), ulcers, and decreased sex drive. 
Recently, chewing khat has become a common practice among high school, college, and university students for entertainment purposes and because they believe it increases their academic performance [3, 4]. The World Health Organization (WHO) has classified khat as an antidepressant drug that can produce mild to moderate mental retardation [5 - 6]. According to the WHO, chronic use of khat can lead to a variety of physical ailments, including urinary retention, weakness, oral cancer, tooth decay, chronic gastritis, hemorrhoids, paralyzed ileus, cirrhosis of the liver, high blood pressure high, and blurred vision. In addition, it can cause reactions to depression and suicide, mania and have effects on the central nervous system, e.g. dizziness, mental retardation, good tremors, insomnia, and headaches. Khat chewers have a much higher mortality rate due to chronic diseases such as heart disease and stroke than non-khat chewing, and chewing khat among teens can increase the risk of contracting HIV and other sexually transmitted diseases [7]

\section{Material and Methods:}

The study was separate. Dated February 2021. Students during study time $(\mathrm{n}=377)$ were included, responding to 302 students (response rate $=80.01 \%$ ).

The information was collected through personal interviews and completed a list of questions that were prepared after reviewing where all questions were related to the objectives mentioned above. Information about gender, distance, place of residence, academic achievement, economic status, and family history of Khat chewing was collected for all non-academic and nonconservative students. Data about the time of chewing, the cause of chewing, the difficulty of chewing, the amount of Khat per day, the purpose of stopping chewing, knowing the dangers of chewing, the idea of chewing, the effect of chewing Khat on social life, the effect of chewing Khat on personality and mind chewing Khat chewed were collected from students be Khat chewing only.

\section{Statistical Analysis:}

The data collected was coded and analyzed using a social science statistics package (SPSS, version 15). The w2 test was used as a value test, and the difference was considered significant at a P-value of 0.05 or less.

\section{Result and Discussion}

Table (1) shows the percentage distribution of university students who have studied according to Khat chewing, Dire Dawa University, the town of Dire Dawa, Ethiopia. Khat chewing was 102 (33.8\%) and non- Khat chewers were 200 (66.2\%), no ex. Khat chewers are found among university students.

Table (1): Percentage distribution of the studied university students according to Chewing Khat status

\begin{tabular}{|l|l|l|}
\hline Smoking & No. & $\%$ \\
\hline Khat chewers & 102 & 33.8 \\
\hline Non-chewers & 200 & 66.2 \\
\hline Total & $\mathbf{3 0 2}$ & $\mathbf{1 0 0 . 0}$ \\
\hline
\end{tabular}

Table (2) shows the relationship between the characteristics of a particular student and the nature of Khat's chewing for university students. Males (88.2\%) of the university responding students chewed with a significant difference $(\mathrm{P}<0.001)$ between males and females regarding chewing. The year of student study, academic achievement, and family history of Khat chewing had a significant impact $(\mathrm{P}<0.05)$ on students chewing the habit. On the other hand, no significant 
differences were found between students living in different areas and groups of economic conditions in terms of chewing.

Table (2): The relationship between some student's characteristics and Khat chewing status in the studied university students $(\mathrm{N}=302)$

\begin{tabular}{|c|c|c|c|c|}
\hline Parameters & Chewers $(\mathrm{N}=102)$ & Non chewers $(\mathrm{N}=200)$ & Total $(N=302)$ & \multirow{2}{*}{ P value } \\
\hline Gender & No. $(\%)$ & No. $(\%)$ & No. $(\%)$ & \\
\hline Male & $90(88.2)$ & $70(35.0)$ & $160(53.0)$ & \multirow{2}{*}{0.000} \\
\hline Female & $12(11.8)$ & $130(65.0)$ & $142(47.0)$ & \\
\hline \multicolumn{5}{|c|}{ Year of study of university student } \\
\hline 1st year & $18(17.6)$ & $56(28.0)$ & $74(24.5)$ & \multirow{5}{*}{0.02} \\
\hline $2^{\text {nd }}$ year & $18(17.6)$ & $4(2.0)$ & $22(7.3)$ & \\
\hline 3rd year & $28(27.5)$ & $74(37.0)$ & $102(33.8)$ & \\
\hline $4^{\text {th }}$ year & $22(21.6)$ & $26(13.0)$ & $48(15.9)$ & \\
\hline $5^{\text {th }}$ year & $16(15.7)$ & $40(20.0)$ & $56(18.5)$ & \\
\hline \multicolumn{5}{|l|}{ Residence } \\
\hline Urban & $96(94.1)$ & $196(98.0)$ & $292(96.7)$ & \multirow{2}{*}{0.44} \\
\hline Rural & $6(5.9)$ & $4(2.0)$ & $10(3.3)$ & \\
\hline \multicolumn{5}{|c|}{ Educational achievement } \\
\hline Excellent & $16(15.7)$ & $80(40.0)$ & $96(31.8)$ & \multirow{4}{*}{0.01} \\
\hline Very good & $36(35.3)$ & $66(33.0)$ & $102(33.8)$ & \\
\hline Good & $32(31.4)$ & $50(25.0)$ & $82(27.2)$ & \\
\hline Accepted\& weak & $18(17.7)$ & $4(2.0)$ & $22(7.3)$ & \\
\hline \multicolumn{5}{|l|}{ Economic status } \\
\hline High & $44(43.1)$ & $92(46.0)$ & $136(45.0)$ & \multirow{3}{*}{0.53} \\
\hline Middle & $52(51.0)$ & $106(53.0)$ & $158(52.3)$ & \\
\hline Low & $6(5.9)$ & $2(1.0)$ & $8(2.6)$ & \\
\hline \multicolumn{5}{|c|}{ Family history of Khat chewing } \\
\hline Yes & $88(86.3)$ & $132(66.0)$ & $220(72.8)$ & \multirow{2}{*}{0.01} \\
\hline No & $14(13.7)$ & $68(34.0)$ & $82(27.2)$ & \\
\hline
\end{tabular}

Table (3) shows the age at onset, type, and causes of Khat chewing among Khat chewer students, $35.2 \%$ of chewing Khat students begin chewing when they are $<15$ years old. Of the university students who chewed $35.6 \%$ reported that they chewed in the morning and afternoon and $25.5 \%$ reported that peer pressure was their cause of chewing Khat.

Table (3): Age at beginning, type, and causes of chewing Khat among studied chewer university students $(\mathbf{n}=102)$

\begin{tabular}{|l|l|l|}
\hline Parameters & No. & $\%$ \\
\hline Age at beginning of chewing khat & & \\
\hline Less than 15 years & 36 & 35.2 \\
\hline $15-$ & 62 & 41.3 \\
\hline 18 years or more & 24 & 23.5 \\
\hline Time of chewing khat & & \\
\hline Morning & 34 & 33.3 \\
\hline Afternoon & 32 & 31.3 \\
\hline
\end{tabular}




\begin{tabular}{|l|l|l|}
\hline Both morning and afternoon & 36 & 35.6 \\
\hline Causes of chewing khat & & \\
\hline Peer pressure & 26 & 25.5 \\
\hline Father or brother pressure & 8 & 7.8 \\
\hline Trying to calms down & 10 & 9.8 \\
\hline For experience & 18 & 17.6 \\
\hline Sense of boring & 4 & 3.9 \\
\hline Multiple causes & 36 & 35.2 \\
\hline
\end{tabular}

Table (4) shows the frequency of Khat chewing, the pattern of daily use, and the concept of chewing Khat of addiction among university students who have studied Khat chewer. Of the university students studying Khat chewing, $70.6 \%$ of Khat chewing students reported that they used to chew daily and $33.4 \%$ reported chewing $1 / 2$ Kilo or more daily. However, $60.8 \%$ reported that they had the idea that Khat chewing was addictive.

Table (4): Frequency, daily consumption pattern and sense of khat chewing addiction among studied khat chewers university students, $(n=102)$

\begin{tabular}{|l|l|l|}
\hline Parameters & No. & $\%$ \\
\hline Frequency of khat chewing & \multicolumn{1}{l|}{} \\
\hline Daily & 72 & 70.6 \\
\hline Weekly & 12 & 11.8 \\
\hline Experimental & 18 & 17.6 \\
\hline Daily consumption pattern & \multicolumn{1}{|l|}{} \\
\hline $1 / 2$ Kilo or more & 34 & 33.4 \\
\hline 1/4 Kilo & 42 & 41.2 \\
\hline Less than $1 / 4$ Kilo & 26 & 25.5 \\
\hline Sense of khat chewing addiction & 62 & 60.8 \\
\hline Yes & 26 & 25.5 \\
\hline No & 14 & 13.7 \\
\hline Don't know & \multicolumn{2}{|l|}{} \\
\hline
\end{tabular}

Table (5) shows students' perceptions of Khat chewing, the impact of Khat chewing on social life and the personality of the chewer, and the purpose of stopping chewing among university students studying Khat chewing. The majority of Khat chewer students $(82.4 \%)$ considered chewing Khat as dangerous and 56.9\% considered chewing Khat to have a positive impact on social health and $64.7 \%$ considered chewing Khat to have a positive effect on their personality. However, only $66.7 \%$ of Khat chewer students reported intending to stop chewing Khat.

Table (5): Students opinion on chewing khat, the impact of chewing khat on social life and chewer's personality and intention to stop khat chewing among studied khat chewer university students, $(n=102)$

\begin{tabular}{|l|l|l|}
\hline Parameters & No. & $\%$ \\
\hline Opinion on chewing khat & & \\
\hline Hazardous & 84 & 82.4 \\
\hline Has benefits & 4 & 3.9 \\
\hline Has neither benefits nor hazards & 2 & 2.0 \\
\hline Has benefits and hazards & 8 & 7.8 \\
\hline
\end{tabular}




\begin{tabular}{|l|l|l|}
\hline Don't know & \multicolumn{2}{l|}{} \\
\hline Impact of chewing khat on social life & 3.9 \\
\hline Good & 58 & 56.9 \\
\hline Bad & 30 & 29.4 \\
\hline Don't know & 14 & 13.7 \\
\hline Impact of chewing khat on personality & \multicolumn{2}{|l|}{} \\
\hline Good & 66 & 64.7 \\
\hline Bad & 16 & 15.7 \\
\hline Don't know & 20 & 19.6 \\
\hline Intention to stop chewing khat & \multicolumn{1}{|l|}{} \\
\hline Yes & 68 & 66.7 \\
\hline No & 34 & 33.4 \\
\hline
\end{tabular}

\section{Discussion}

The prevalence of Khat chewing among university students in the current study was $33.8 \%$ of students responding to universities. The current study revealed a significant difference ( $P$ $<0.001)$ between males and females regarding chewing. In addition, the results showed that that year of university student study and family history of Khat chewing had a significant impact on Khat chewing for university students $(\mathrm{P}<0.05)$. On the other hand, the social and economic outcomes for students chewing were not significant $(\mathrm{P}>0.05)$.

The results showed that $76.5 \%$ of Khat chewer university students started chewing at the age of 18. Of the students who Khat chewer $25.5 \%$ reported that the cause of chewing was peer pressure. Regarding the difficulty of chewing Khat $70.6 \%$ of Khat chewers, University students reported that they chew daily.

In the current study, $66.7 \%$ of university students studying Khat chewer reported that they intended to stop chewing. Current research has shown that all students studying at university are aware of the dangers of chewing Khat.

\section{Conclusion}

Chewing Khat among university students is considered a major problem because they will be future employees who should play a key role in helping adults to stop chewing. Efforts are needed to help students stop chewing Khat and this is seen as a way to prevent the problem of chewing Khat from future employees. Anti- Khat chewing education should be included in student degree courses, as well as launching anti-chewing campaigns.

\section{References:}

[1].Gebrie, A., Alebel, A., Zegeye, A., \& Tesfaye, B. (2018). Prevalence and predictors of khat chewing among Ethiopian university students: a systematic review and metaanalysis. PLoS One, 13(4), e0195718.

[2].Abdeta, T., Tolessa, D., Adorjan, K., \& Abera, M. (2017). Prevalence, withdrawal symptoms and associated factors of khat chewing among students at Jimma University in Ethiopia. BMC psychiatry, 17(1), 1-11.

[3].Kassa, A., Wakgari, N., \& Taddesse, F. (2016). Determinants of alcohol use and khat chewing among Hawassa University students, Ethiopia: a cross-sectional study. African health sciences, 16(3), 822-830. 
[4]. Astatkie, A., Demissie, M., Berhane, Y., \& Worku, A. (2015). Prevalence of and factors associated with regular khat chewing among university students in Ethiopia. Substance abuse and rehabilitation, 6,41 .

[5].Gebrehanna, E., Berhane, Y., \& Worku, A. (2014). Khat chewing among Ethiopian University Students-a growing concern. BMC public health, 14(1), 1-7.

[6]. Kebede, Y. (2002). Cigarette smoking and Khat chewing among college students in North West Ethiopia. Ethiopian Journal of Health Development, 16(1), 9-17.

[7].Dachew, B. A., Bifftu, B. B., \& Tiruneh, B. T. (2015). Khat use and its determinants among university students in northwest Ethiopia: a multivariable analysis. Int J Med Sci Public Health, 4(3), 319-23.

[8]. Mustefa JIBRIL. A Study of Emotional Intelligence of Electrical Engineering students in Dire Dawa

[9]. University Ethiopia. Rep Opinion 2021;13(7):5-7]. ISSN 1553-9873 (print); ISSN 23757205 (online). http://www.sciencepub.net/report. 2. doi:10.7537/marsroj130721.02.

[10]. Mustefa JIBRIL." Evaluation on Study Skills and Academic Stress on University Engineering Student' s Academic Achievement " ACE Journal of Humanities, Social Sciences and Education, ISSN: 2520 - 3827, Volume 1, Number 2, Page No. 18 - 23, 2021

[11]. Mustefa JIBRIL." Evaluation on Success of Graduating with Distinction in Higher Education using Fuzzy DEMATEL Method" ACE International Journal of Social Sciences, ISSN: 2520 - 3177, Volume 1, Number 1, Page No. 1 - 5, 2021

[12]. Mustefa JIBRIL.” The Attitude of Students Concerning Gender and Rural Urban Dichotomy in Dire Dawa University" ACE International Journal of Social Sciences, ISSN: 2520 - 3177, Volume 1, Number 3, Page No. 28 - 34, 2021

[13]. Mustefa JIBRIL. The Attitude of Students Towards Learning English Language at Secondary Schools in Dire Dawa Ethiopia. Academia Arena 2021;13(7):61-64]. ISSN 1553-992X (print); ISSN 2158-771X (online), http://www.sciencepub.net/academia. 4. doi:10.7537/marsaaj130721.04.

[14]. Mustefa JIBRIL." The Evaluation Between Importance of Educational Needs and Satisfaction about it as Perceived by Engineering Students at Dire Dawa University Ethiopia” ACE International Journal of Social Sciences, ISSN: 2520 - 3177, Volume 1, Number 2, Page No. 19 - 24, 2021

[15]. Mustefa JIBRIL The Impact of adjustment on Academic achievement among University Students in Dire Dawa Ethiopia. N Y Sci J 2021;14(7):17-20]. ISSN 15540200 (print); ISSN 2375-723X (online). http://www.sciencepub.net/newyork. 3. doi:10.7537/marsnys140721.03.

[16]. Mustefa JIBRIL." The Impact of Gender on Adjustment Level of Dire Dawa University Lecturers” ACE International Journal of Social Sciences, ISSN: 2520 3177, Volume 1, Number 2, Page No. 13 - 15, 2021 